\title{
A Fusion Chamber Design with a Liquid First Wall and Divertor
}

R.E. Nygren, D.K. Sze, B.E. Nelson, P.J. Fogarty, C. Eberle, T.D. Rognlien, M.E. Rensink, S. Smolentsev, M.Z. Youssef, M.E. Sawan, B.J. Merrill, R. Majeski

November 12, 2003

20th Symposium on fusion Engineering San Diego, CA, United States

October 14, 2003 through October 17, 2003 
This document was prepared as an account of work sponsored by an agency of the United States Government. Neither the United States Government nor the University of California nor any of their employees, makes any warranty, express or implied, or assumes any legal liability or responsibility for the accuracy, completeness, or usefulness of any information, apparatus, product, or process disclosed, or represents that its use would not infringe privately owned rights. Reference herein to any specific commercial product, process, or service by trade name, trademark, manufacturer, or otherwise, does not necessarily constitute or imply its endorsement, recommendation, or favoring by the United States Government or the University of California. The views and opinions of authors expressed herein do not necessarily state or reflect those of the United States Government or the University of California, and shall not be used for advertising or product endorsement purposes. 


\title{
A Fusion Chamber Design with a Liquid First Wall and Divertor
}

\author{
R.E. Nygren, D.K. Sze ${ }^{a}$, B.E. Nelson ${ }^{b}$, P.J. Fogarty ${ }^{b}$, C. Eberle ${ }^{b}$, T.D. Rognlien ${ }^{c}$, M.E. Rensink ${ }^{c}$, \\ S. Smolentsev ${ }^{\mathrm{d}}$, M.Z. Youssef ${ }^{\mathrm{d}}$, M. E. Sawan ${ }^{\mathrm{e}}$, B.J. Merrill ${ }^{\mathrm{f}}$ and R. Majeski ${ }^{\mathrm{g}}$ \\ Sandia National Laboratories" , PO Box 5800, Albuquerque, NM 87185 \\ ${ }^{a}$ University of California, San Diego, 9500 Gilman Drive, La Jolla, CA 92093-0417 \\ ${ }^{b}$ Oak Ridge National Laboratory, P.O. Box 2008, Oak Ridge, TN 37831 \\ ${ }^{c}$ Lawrence Livermore National Laboratory, 7000 East Ave., Livermore, CA 94550-9234 \\ ${ }^{d}$ University of California, Los Angeles, MAE Dept. Box 951597, Los Angeles, CA 90095-1597 \\ ${ }^{e}$ University of Wisconsin, Madison; Madison, WI 53706 \\ ${ }^{f}$ Idaho National Engineering and Environmental Laboratory, P.O. Box 1625, Idaho Falls, ID 83415 \\ ${ }^{g}$ Princeton Plasma Physics Laboratory, P.O. Box 451, Princeton, NJ 08543-0451
}

\begin{abstract}
The APEX study is investigating the use of free flowing liquid surfaces to form the inner surface of the chamber around a fusion plasma. We present a design for the chamber of a $3840 \mathrm{MW}$ fusion reactor based on the configuration for the chamber and magnets from ARIESRS but with a fast flowing molten salt of mixed $\mathrm{Be}, \mathrm{Li}$ and Na fluorides for the first wall and divertor and molten salt blanket with a ferritic steel structure. Our design analysis includes strong radiation from the core and edge plasma, (liquid) MHD effects on the weakly conducting molten salt, a recycling first wall stream that enables a high efficiency thermal conversion, and evaluations of breeding, neutronics, tritium recovery and safety:
\end{abstract}

\section{INTRODUCTION}

This paper briefly summarizes a design for the chamber of a magnetic fusion reactor with flowing liquid walls facing the plasma. While removing surface heat, the continuously-renewed liquid surface is unaffected by the radiation damage and thermal stresses that limit the performance of solid chamber walls. A companion paper summarizes the divertor design[1] and a longer paper[2] provides more detail and includes extensive references and discussions of R\&D issues. The design effort, part of the Advanced Power Extraction (APEX) study[3], utilizes work on plasma interactions with liquid surfaces performed in the Advanced Limiter-Divertor Plasma Facing Systems (ALPS) study[4]. The ideas for fusion reactors with liquid metals and even liquids with free surfaces are not all new[5-23], but new ideas have been developed in APEX and the depth of the underlying science and engineering exceeds previous work.

Chamber technology serves two of three fundamental functions of fusion energy systems. The first is confining the plasma itself. The second and third are (1) breeding of sufficient tritium to fuel a self-sustained reactor, and (2) practical, reliable, safe, economical power extraction. Economics pushes fusion toward high power density and high-temperature coolants; these set requirements for

* $*$ Sandia is a multi-program laboratory operated by Sandia

Corporation, a Lockheed Martin Company, for the United States

Department of Energy under Contract DE-AC04-94AL85000. tritium breeding and heat removal.[3] Three principal features of the fusion chamber are the (1) first wall and divertor, (2) the blanket, and (3) the shield (Fig. 1). We also include supporting systems such as those for tritium processing and heat exchange. We have adapted the basic magnetic configuration from an existing design study for a $2170 \mathrm{MW} \mathrm{D/T}$ fusion power plant called ARIES-RS[24,25] with 16 toroidal field coils, a major radius of $5.5 \mathrm{~m}$ and aspect ratio of 4 , and incorporated a liquid surface first wall and divertor and a liquid blanket.

We have explored mechanical designs for several concepts and each has included detailed CAD renderings and several innovative features.[2] In 1999-2000, we studied a design with the molten salt Flibe as the working liquid, and, in 2000-2001, designs with Li and with Sn-Li. Excessive surface temperature (vaporization of F) limited the Flibe design, and poor thermal efficiency due to the relatively low temperature for evaporation of Li limited the Li design.[26] In 2001 we began designs with a $\mathrm{Sn}$ first wall and $\mathrm{Pb}-\mathrm{Li}$ blanket. The analysis of plasma surface interactions gave a fairly good operating temperature range with the surface temperature limit of $\mathrm{Sn}$ being $810-840^{\circ} \mathrm{C}$ for the $\mathrm{FW}$ and $1630^{\circ} \mathrm{C}\left(1480^{\circ} \mathrm{C}\right.$ for $\left.\mathrm{Ga}\right)$ for the divertor. Simple correlations for the MHD forces and the assumption of an insulating wall showed that $\sim 20 \mathrm{~mm}$-thick flow streams launched at $10 \mathrm{~m} / \mathrm{s}$ would flow down and adhere to concave substrate. The difficulty of modeling the magneto-hydrodynamic (MHD) effects that dominate the fluid flow precluded more detailed analyses, and this area is being actively investigated through both modeling and experimental work in APEX.[27]

We refer readers to another paper[2] for descriptions of many innovative features. For example, in utilizing a Sn-Li mixture, the lower activity of the Li in the mixture and lower evaporation rate raised the allowable surface temperature of the first wall from $380^{\circ} \mathrm{C}$ for $\mathrm{Li}$ to $590^{\circ} \mathrm{C}$ for $0.8 \mathrm{Sn}-0.2 \mathrm{Li}[28,29]$, and segregation of $\mathrm{Li}$ to the surface (driven by a reduction in the surface tension) was also identified as an issue and possible benefit.[30] 

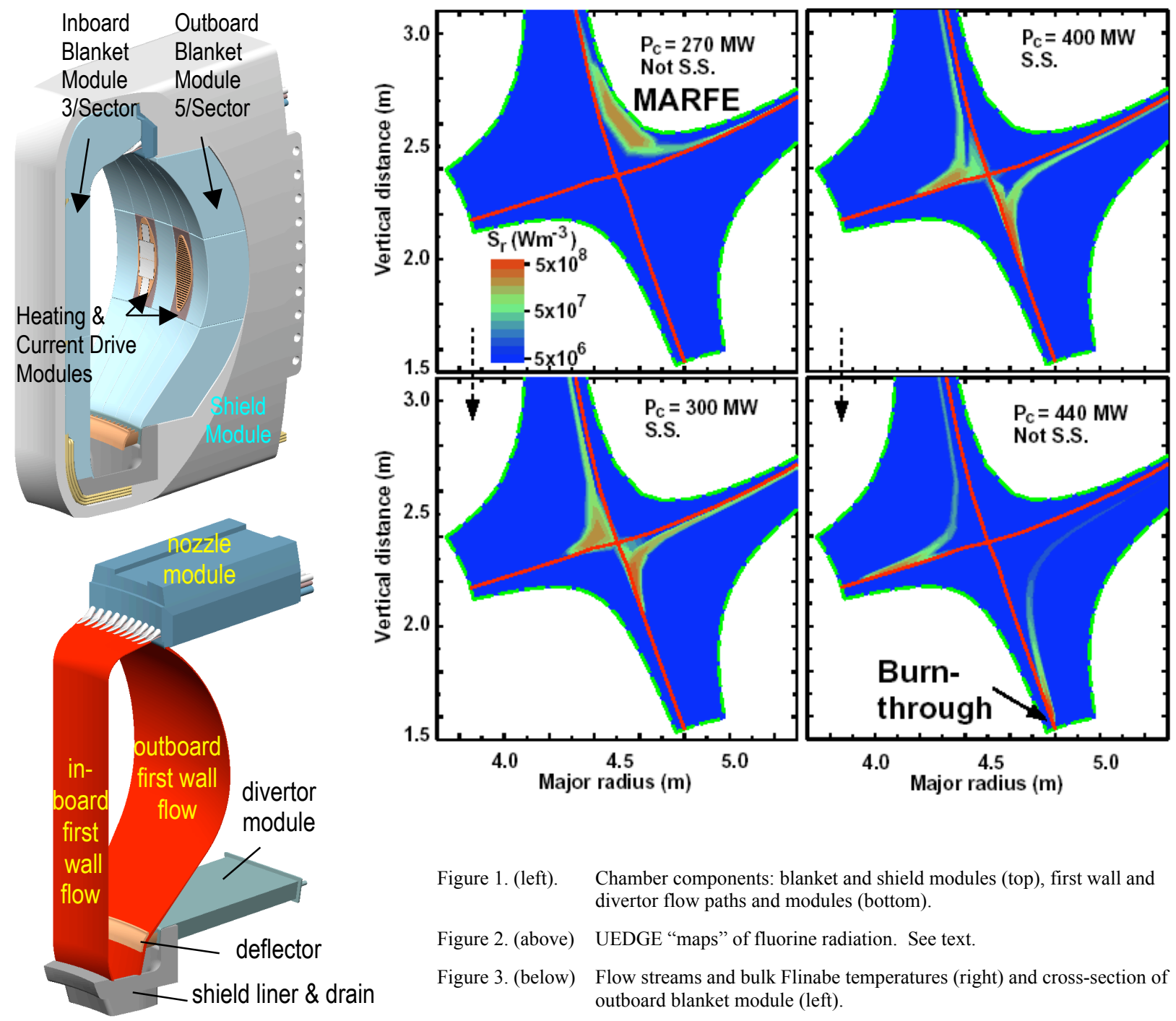

Figure 1. (left). Chamber components: blanket and shield modules (top), first wall and divertor flow paths and modules (bottom).

Figure 2. (above) UEDGE "maps" of fluorine radiation. See text.

Figure 3. (below) Flow streams and bulk Flinabe temperatures (right) and cross-section of outboard blanket module (left).
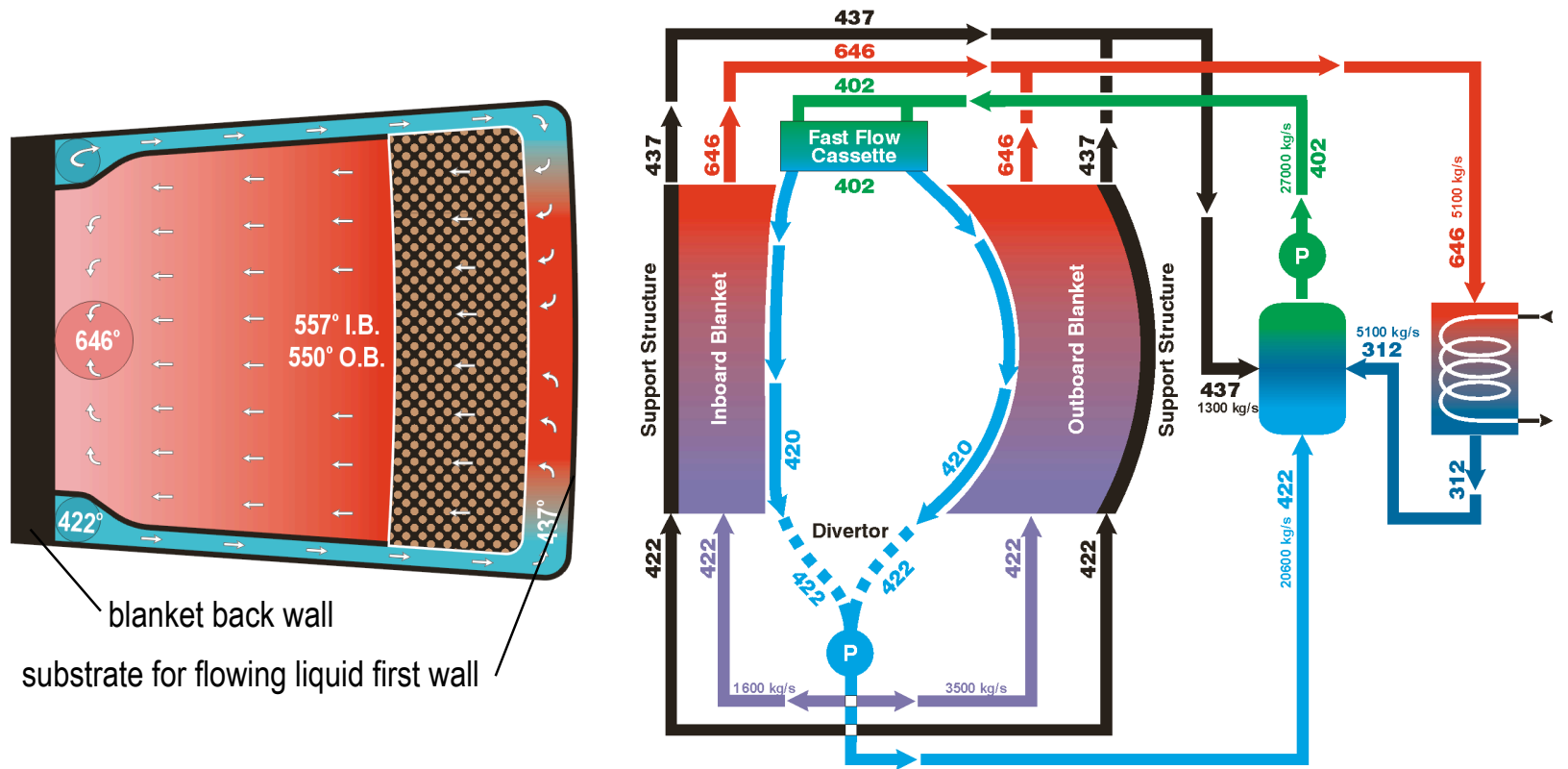
Other examples include modifiying the flow substrate to improve flow around penetrations, flexible $\mathrm{SiC}$ bags that contained the liquid blanket, and "self shielding" nozzles invented by authors Nelson and Fogarty.

In our designs, modeling of the plasma edge defines the heat loads, and thermal-hydraulic analyses show that the heat removal is adequate. Evaluation of thermal transport shows an operating point with reasonable thermal efficiency and neutronic analyses show adequate tritium breeding. Evaluations of safety indicate manageable approaches to the issues. Since our focus is on chamber technology, we do not develop descriptions of the magnets, balance of plant, reactor hall, etc.

In FY2002 we began our design with the molten salt, Flinabe, described later. It has similarities to Flibe but a lower melting point. We began with some skepticism since molten salts have poor thermal conductivity and good thermal conductivity would seem to be an a priori requirement for any first wall and divertor material. In this regard, our APEX/ARIES design with Flinabe is a startling and pleasing result.

\section{CHAMBER CONFIGURATION}

In our adaptation of ARIES-RS, we increased the power density by specifying a fusion power of $3840 \mathrm{MW}$ to define the heat loads for the first wall and divertor, so that a total power of $909 \mathrm{MW}$ (767 MW alpha power, $142 \mathrm{MW}$ auxiliary power) will be transmitted as surface heat loads to the first wall and divertor (Table 1).

TABLE I

POWER BALANCE PARAMETERS FOR APEX CHAMBER SYSTEM

$\begin{array}{lcl}\text { First wall area } & 434 \mathrm{~m}^{2} \\ \text { Average neutron wall loading } & 7.08 \mathrm{MW} / \mathrm{m}^{2} \\ \text { Average surface heat flux } & 1.76 \mathrm{MW} / \mathrm{m}^{2} \\ \text { Fusion power } & 3840 \mathrm{MW} \\ \text { Alpha power } & 767 \mathrm{MW} \\ \text { Auxiliary power to plasma } & 142 \mathrm{MW} \\ \text { Power to the first wall } & 765 \mathrm{MW} \\ \text { FW nuclear heating } & 400 \mathrm{MW} \\ \text { Total power removed by FW } & 1165 \mathrm{MW} \\ \text { Power to the divertor } & 144 \mathrm{MW} \\ \text { FW surface heat flux, average } & 1 \mathrm{MW} / \mathrm{m}^{2} \\ \text { FW surface heat flux, maximum } & 3 \mathrm{MW} / \mathrm{m}^{2} \\ \text { Neutron power } & 3073 \mathrm{MW} \\ \text { Neutron wall loading, average } & 7 \mathrm{MW} / \mathrm{m}^{2} \\ \text { Neutron wall loading, maximum } & 10 \mathrm{MW} / \mathrm{m}^{2} \\ \text { Blanket energy multiplication } & 1.06 \\ \text { Blanket thermal power } & 3257 \mathrm{MW} \\ \text { Total thermal power } & 4024 \mathrm{MW} \\ \text { Total power (thermal + aux.) } & 4166 \mathrm{MW}\end{array}$

In high power density devices, a large fraction of the alpha power must be converted into radiation to make the heat load on the divertor manageable. While large radiative cooling can mitigates the peak heat loads, it also tends to decrease the thermal isolation and stability of the core plasma. In our design, strong radiation from the core plus strong radiation from the divertor region is used to reduce the peak heat load in the divertor and balance the power loads of the divertor and first wall. The power to the first wall of $765 \mathrm{MW}$ is $84 \%$ of the total particle power of $909 \mathrm{MW}$ while the balance of power to the divertor (144 MW) is only $16 \%$.

The recent plasma transport modeling by Rognlien and Rensink, finds a stable operating window for a highly radiating edge plasma including steady state modeling solutions in which about $95 \%$ of the power coming into the scrape-off layer is radiated near the X-point for alpha powers in the range of 300-360 MW. This work is described briefly in our companion paper[1] and elsewhere[2,31]. Figure 2 shows a sample result for a series of solutions at progressively higher values of $\mathrm{P}_{c}$, power convected from the plasma core into the edge plasma. The plots are maps of flourine radiation in the lower portion of the chamber cross section with strong impurity line-radiation concentrated near the X-point and below. The set of four cases shows a progression from a case that is not stable (MARFE), through two cases (300 and $400 \mathrm{MW}$ ) with stable operation, to the $440 \mathrm{MW}$ case that is unstable and "burns through" onto the target. The $300 \mathrm{MW}$ case had a peak heat flux (particle + radiation) at the divertor plate of only $\sim 8$ $\mathrm{MW} / \mathrm{m}^{2}$ and a peak heat flux to the first wall of $\sim 2$ $\mathrm{MW} / \mathrm{m}^{2}$ for a density at the edge of the core of $\sim 1.5 \times 10^{20}$ $\mathrm{m}^{-3}, \mathrm{H}(\mathrm{D} / \mathrm{T})$ throughput of $\sim 3.1 \times 10^{23}$ particles/s with divertor plates orthogonal to magnetic flux surfaces and $\mathrm{H}$ pumped at private flux surface for stability. The Fluorine density at core boundary varies poloidally over the range $3.7-7.3 \times 10^{17} \mathrm{~m}^{-3}(0.24 \%-0.49 \%$ of hydrogen; $1 \%$ is the limit based on core radiation loss). This work supports the conclusion that it is reasonable to investigate designs based upon relatively modest peak heat fluxes $\left(8-10 \mathrm{MW} / \mathrm{m}^{2}\right)$ in the divertor.

\section{Flow PATHS AND HEAT TRANSFER}

Fig. 3 shows the flow streams and bulk temperatures. The inboard and outboard first wall streams flow from a set of nozzles at the top of the chamber that inject the Flinabe onto the front surfaces of the blanket modules. One set of nozzles feeds the inner first wall, another set feeds the outer first wall. The overlapping streams from the "self-shielding" nozzles prevent any line-of-sight from the plasma directly to a nozzle.[2]

The thickness of the first wall flow at midplane is 23 $\mathrm{mm}$ and the flow speed is $10 \mathrm{~m} / \mathrm{s}$. The first wall flow length is $\sim 6.5 \mathrm{~m}$. The Flinabe starts at $402^{\circ} \mathrm{C}$ and rises to $420^{\circ} \mathrm{C}$ at the bottom of the first wall. The penetration of the surface heat and nuclear heating contribute about equally to the rise in bulk temperature of $\sim 18^{\circ} \mathrm{C}$. The surface temperature, which reaches $509^{\circ} \mathrm{C}$ at the bottom of the first wall, was calculated by Smolentsev using a 
fluid flow and heat transfer model that includes MHD (magneto-hydrodynamic) effects.[2,32] The approach is based on the standard " $\mathrm{K}$-_" model used widely in engineering applications to characterize turbulent flow, and was modified by Smolentsev and others to include the effects of MHD on the turbulence, particularly in the region of fluid near the free surface. While the MHD effect on the flow thickness (or speed) was minimal for Flinabe, the effect on heat transfer in the near surface was significant ${ }^{1}$. Freeze and Smolentsev[33] have also investigated the effect of waviness on the heat transfer. For our design, the impact of the magnetic field on the wave motion is still not clear and we typically show two curves. Both include the effect of the MHD on turbulence. The rise in surface temperature for Flinabe without the effect of waviness is $130^{\circ} \mathrm{C}$ and $90^{\circ} \mathrm{C}$ with the waviness.[2] So the maximum estimated surface temperature of the first wall is $532^{\circ} \mathrm{C}$ without the advantage of the wavy flow and $492^{\circ} \mathrm{C}$ with waviness. Since we anticipate that some waviness will occur, we conclude that the maximum surface temperature will not exceed the allowable maximum surface temperature of $510^{\circ} \mathrm{C}$, and the first wall power handling is adequate.

Near the bottom of the chamber, these first wall streams become the inboard and outboard divertor flow ${ }^{2}$. This flow differs from the first wall flow in four ways: (1) the divertor streams are separated at the sector boundaries by the deflector and guided into the exhaust ducts; (2) charged particles carrying a high heat load graze the divertor surface, so a protrusion (bump or wave) collects a large heat flux; (3) higher peak heat load; and (4) MHD forces from the radial and poloidal components in the field and gradients along the divertor surface.

The heat load and temperature rise in the divertor are discussed in our companion paper.[1] In the divertor, charged particles hitting the surface at the "strike point" produce a peaked heat load. The radiative heat load comes primarily from the strongly radiating zones near the null point in the separatrix. Charge exchange neutrals and radiation from the main plasma also contribute lesser amounts to the heat load. In our design calculations, the peak heat load in the outboard divertor of $10-12 \mathrm{MW} / \mathrm{m}^{2}$ is approximated by a flat profile with a

\footnotetext{
${ }^{1}$ In general in the presence of a strong magnetic field, the turbulent eddies in the bulk of the fluid tend toward a 2-D state with circulation around the direction of the magnetic field and elongation along the field. The turbulent structure is anisotropic; near the free surface there is also a damping of turbulent transport and turbulence redistribution. In these flows, one must characterize separately the turbulence in the bulk fluid and the turbulence near the free surface. See Ref. [2].

${ }^{2}$ Since a rapid flow for the blanket does not lead to a workable design for several reasons, this approach, with a single fast stream for the first wall and divertor, is the simplest implementation for the chamber flow. Introducing a separate divertor stream offers the potential advantages of separate control for fluid parameters such as inlet velocity and temperature but also introduces the complexity of a separate flow loop.
}

peak of $10.6 \mathrm{MW} / \mathrm{m}^{2}$ that is the sum of the uniform radiated heat flux onto the entire divertor surface of $\sim 3$ $\mathrm{MW} / \mathrm{m}^{2}$ plus $7.6 \mathrm{MW} / \mathrm{m}^{2}$ over the peak. The rise in surface temperature for the divertor stream is about $135^{\circ} \mathrm{C}$; this, added to the bulk temperature of $420^{\circ} \mathrm{C}$ leaving the first wall gives a peak of about $555^{\circ} \mathrm{C}$. This is higher than the allowable temperature of $510^{\circ} \mathrm{C}$ for the first wall, but is acceptable in the divertor where there is more shielding of impurities from the main plasma.

Below the divertor, the inner and outer fluid streams join in the upper part of the exhaust ducts and flow out of the bottom of the chamber through this duct. The pumping duct is protected with a removable shield liner (Fig. 1) that also provides radiation shielding for the duct wall and magnets. The duct ( $1 \mathrm{~m}$ dia.) is large enough to carry the flowing fluid and provide sufficient conductance for pumping exhaust gases. Even if the flow velocity dropped from $10 \mathrm{~m} / \mathrm{s}$ in the divertor to 5 $\mathrm{m} / \mathrm{s}$ in the duct, the duct would only be $1 / 3$ full.

The second fluid flow circuit is for the inner and outer blankets (Fig. 3). The radial build of the inboard blanket is $544 \mathrm{~mm}$; that of the outboard blanket is $644 \mathrm{~mm}$. Both have a $5 \mathrm{~mm}$ front wall, $40 \mathrm{~mm}$ Flinabe plenum and $60 \mathrm{~mm}$ beryllium bed (57\% packing density). The walls are advanced ferritic steel. The main breeding region at the back of the blanket is $400 \mathrm{~mm}$ deep in the inner blanket and $500 \mathrm{~mm}$ deep in the outer blanket. An inner blanket module extend $7.5^{\circ}$ toroidally and an outer module $4.5^{\circ}$. The blanket collects about $80 \%$ of the heat produced by the reactor. The Flinabe flow enters each side channel of the blanket at $422^{\circ} \mathrm{C}$ and $0.18 \mathrm{~m} / \mathrm{s}$, flows to the front and then enters the multiplier region at $483^{\circ} \mathrm{C}$ and flows at $0.013 \mathrm{~m} / \mathrm{s}$ into the interior space most of which is an open volume. The pressure drop through the bed is $0.02 \mathrm{MPa}$ and is small elsewhere. The flow path must be designed to avoid stagnation points and local hot spots that could lead to degradation of the walls or beryllium balls.

\section{ENERGY CONVERSION AND MATERIALS}

For good power conversion efficiency, we need a large operating temperature window. The power balance in our design is based on (a) the distribution of the alpha and auxiliary power plus (b) the management of coolant flow that includes a recirculating stream for the first wall, shown in Figure 3. For our liquid surface chamber designs, the limit for impurities evaporated from the wall, as determined from plasma edge modeling, set the maximum surface temperature of the first wall (or divertor), which is in turn related to the bulk temperature of the fluid through the heat transfer described above. The minimum fluid temperature (exit of heat exchanger) usually depends solely on the choice of fluid and is set so that the fluid does not freeze or become too viscous or precipitate solids in cold spots. 
An obvious concern as we considered a fast flowing first wall was that the coolant temperature rise $\left(T_{\text {out }}-T_{\text {in }}\right)$ in this stream would be very small. Our solution is to have only a small fraction of the first wall coolant (5100 of $27,000 \mathrm{~kg} / \mathrm{s}$ ) pass through the blanket and go to the power conversion system, while the remainder is recirculated. With this solution there is some parasitic "cost" in the power required for recirculation of Flinabe through the first wall (and a minor amount to the support structure), but overall we believe this is an effective solution. The Flinabe stream from the blanket heats to $646^{\circ} \mathrm{C}$, which is an attractive outlet temperature for power conversion. We estimate the power conversions efficiency to be $49 \%$.

The molten salt Flinabe is a mixture of three fluorides; the nominal 1:1:1 mixture is LiF-NaF-BeF2. We have little data on the physical properties of Flinabe; we believe these are similar to Flibe, but with a lower melting temperature and the same $\mathrm{BeF} 2$ concentration at the same temperature. Flibe is a mixture of $\mathrm{LiF}$ and $\mathrm{BeF}$ that was studied for use in molten salt fission reactors (and actinide burners) but much of the data are in laboratory technical reports.[34-36] Good data compilations also were done in the past for the HYLIFEII study[37], a heavy-ion driver inertial fusion power plant, and for the Blanket Comparison and Selection Study[38]. There has also been a recent assessment of Flibe that discusses its chemistry and the issues associated with tritium processing.[39] The key advantage of Flinabe is its lower melting temperature. The lowest reported melting temperature is $240^{\circ} \mathrm{C}$ but this value is suspect and the melting point is the subject of experiments at Idaho National Engineering and Environmental Laboratory. This lower melting point extends the window of operating temperature enough that a workable design appears possible. The neutron multiplier is a $60-\mathrm{mm}$-thick bed of $5 \mathrm{~mm}$ beryllium pebbles and a packing density of $57 \%$.

The primary structural material for the blanket, and auxiliary structures, is an advanced ferritic steel. The front and side walls of the blanket are $5 \mathrm{~mm}$ thick. The back wall is thicker. It is really the recent developments in the oxide dispersion-strengthened (ODS) ferritic alloys[40,41] and the extension of good mechanical properties to significantly higher temperature that are now bringing renewed interest to the application of ferritics in fusion. One formulation of an ODS ferritic steel being developed at Oak Ridge National Laboratory and designated $12 \mathrm{YWT}$ has $0.25 \%$ of Yttria and superior properties.[40] It appears to have a maximum working temperature of $800^{\circ} \mathrm{C}$ and corresponding yield strength of $320 \mathrm{MPa}$. When used with the molten salt coolant Flibe, the two materials are compatible up to $700^{\circ} \mathrm{C}$.

\section{Mechanical Design}

The mechanical design has been developed by authors Nelson, Fogarty and Eberle to the point that we can see that the design integration of the sectors and piping systems, manifolding, etc. is self-consistent, that the sizes and locations of the piping and ducts are reasonable in terms of the pressure drops, and that the components are amenable to handling for remote maintenance, e.g., all high maintenance components are designed as modules, such as the RF modules, nozzle arrays and the divertor cassette. Ref. [2] lists the modules and their volumes, has CAD drawings showing how the modules nest in the assembly sequence and gives the piping specifications. The first wall flow is represented as 20 -mm-thick layer with the volumetric flow calculated at the midplane. Regarding flow around penetrations, the RF modules are used as an example and we anticipate that smooth flow around penetrations can be managed by a combination of flow separation and wall shaping above the penetration plus auxiliary nozzles at the bottom of the structures so that the downstream "hole" in the wake of the FW fluid flow can be filled with the added fluid. The nozzle system could be incorporated as the outlet for any necessary cooling passages within the structure itself.

Experienced designers have done this work. We believe the designs can be made robust in terms of the mechanical and EM (electromotive) forces that such a structure must withstand. Our objective in this work is to develop nominally workable designs for the chamber technology. We have had neither time nor resources to develop engineering details that would show mechanical response of the structure to various types of off normal events and transient loading that are associated with a detailed engineering design and safety analysis.

\section{NEUTRONICS}

In the molten salt LiF-NaF-BeF2 (Flinabe) the Li atom is in one of three fluoride molecules and its tritium breeding capability is less than that of LiF-BeF2 (Flibe), in which $\mathrm{Li}$ is in one of two molecules. The lower $\mathrm{Li}$ concentration requires a comparatively more of the neutron multiplier beryllium to improve the tritium breeding ratio (TBR). Author Youseff has shown these characteristics for the structural materials, $\mathrm{SiC}$ and ferritic steel (HT-9) in the initial APEX liquid wall and blanket configuration, which was used earlier for assessment of TBR with other liquid breeders[42-46]. Ref. [2] summarizes an initial assessment of tritium breeding and a final assessment, the latter corresponded to the design described here with the blanket having an advanced ferritic steel structure with a 60 -mm-thick Be bed of $57 \%$ packing density. In the space here we can present only a brief summary of the work on tritium breeding and neutronics. 
A one-dimensional model that accounted for both the inboard (IB) and outboard (OB) was used in the analysis. The ANISN 1-D[47] code was used along with 46 neutron-21 gamma multigroup data library based on the FENDL-2 data[48]. The second assessment of TBR used more realistically matched the features of our chamber design. The beryllium zone composed of $4 \% \mathrm{AFS}, 57 \% \mathrm{Be}$, and $39 \%$ Flinabe where as the breeding zone is composed of $4 \%$ AFS and $96 \%$ Flinabe. The total blanket thickness (front Flinabe zone $+\mathrm{Be}$ zone + back Flinabe Zone) is kept at $60 \mathrm{~cm}$ and $40 \mathrm{~cm}$ on the $\mathrm{O} / \mathrm{B}$ and $\mathrm{I} / \mathrm{B}$ side. For a $12-\mathrm{cm}$-thick Be zone, the local TBR is $\sim 1.3$ and is 1.4 for a $\sim 28$-cm-thick Be zone. The local value adopted in the present design is a TBR of $\sim 1.22$ for a thickness of the beryllium zone $\square \mathrm{Be}$ of 6 $\mathrm{cm}(57 \%$ dense), which is equivalent to an effective beryllium thickness $\square_{\Gamma} \mathrm{Be}$ of $3.4 \mathrm{~cm}$. The corresponding TBR $(\sim 1.22)$ is used as the reference value and believed to be adequate in meeting tritium self-sufficiency goal.

Nuclear heating (from both neutrons and gamma rays) has been estimated for various APEX liquid wall (LW) configurations with Flinabe as the coolant and breeder. About $31 \%$ of the total nuclear heat is deposited in the $\mathrm{I} / \mathrm{B}$ whereas the balance $(\sim 69 \%)$ is deposited in the $\mathrm{O} / \mathrm{B}$ at the mid plane. The power deposited in the front flowing liquid layer is $\sim 12-14 \%$ whereas most of the power $(\sim 80-83 \%)$ is deposited in the blanket (excluding its solid front wall).

The required minimum shield thickness, both in the inboard and outboard side, was estimated such that the upper limits to radiation damage to the magnet will not be exceeded. This optimization is needed to eliminate oversized shield and thus reduce cost. This also will allow for more space, particularly on the inboard side, for manifolds and piping to route coolant. The upper limits to radiation damage to the magnet considered in the analysis are: (1) end-of-life fast neutron fluence $(\mathrm{En}>0.1 \mathrm{MeV})$ of $1.0 \times 10^{19} \mathrm{n} / \mathrm{cm} 2$, (2) end-of-life insulator (glass-fiber-filled, GFF, polyimide) dose of $1.0 \times 10^{9}$ Grays $\left(1.0 \times 10^{11}\right.$ rads), (3) end-of-life copper stabilizer of $6 \times 10^{-3} \mathrm{dpa}$, and (4) Peak winding pack power density of $2 \mathrm{~mW} / \mathrm{cm}^{3}$. The good radiation attenuation characteristics of Flinabe resulted in thinner shield. The minimum shield thicknesses, based on endof-life neutron fluences, are $\sim 56 \mathrm{~cm}$ in the inboard side and $\sim 26 \mathrm{~cm}$ in the outboard $\operatorname{side}^{3}$.

The penetration of brehmsstralung radiation (x-rays) in liquids was also investigated because the heating can be spread over a depth rather than being essentially surface heating as for solid walls. This spreading is most

\footnotetext{
${ }^{3}$ The O/B shield thickness of $60 \mathrm{~cm}$ shown for the current design and can be reduced to $26 \mathrm{~cm}$.
}

pronounced for lithium but is also significant for Flinabe, which is similar to Flibe.[49]

Author Sawan performed activation calculations for the Flinabe blanket in the APEX liquid wall concept to determine the generated radioactive inventory and decay heat for the safety analysis.[50] The Flinabe activity is dominated by ${ }^{16} \mathrm{~N}\left(\mathrm{~T}_{1 / 2}=7.13 \mathrm{~s}\right)$ for up to a minute after shutdown and by ${ }^{22} \mathrm{Na}\left(\mathrm{T}_{1 / 2}=2.605 \mathrm{y}\right),{ }^{24} \mathrm{Na}\left(\mathrm{T}_{1 / 2}=\right.$ $14.96 \mathrm{~h})$, and ${ }^{18} \mathrm{~F}\left(\mathrm{~T}_{1 / 2}=1.83 \mathrm{~h}\right)$ at later time. The total Flinabe activity is less than the total structure activity except for the first minute after shutdown. The total ${ }^{24} \mathrm{Na}$ activity is much lower than the total structure activity and is expected not to be a major concern when Flinabe is used in fusion systems.

The decay heat generated in the Flinabe is much larger than that generated in the advanced ferritic structure and should be a concern during a loss of flow accident (LOFA). The waste disposal rating (WDR) of the structure in the blanket is $<0.8$ and is contributed primarily by ${ }^{94} \mathrm{Nb}$ produced from transmutation of Mo. In addition, the Flinabe and Be WDR values are well below unity $(<0.004)$. Hence, all blanket components will qualify as Class $\mathrm{C}$ low level waste.

\section{TRITIUM PROCESSING}

Tritium has a very low solubility in Flibe or Flinabe. The Henry's law constant is only $7 \times 10^{-5}$ moles- $\mathrm{H}_{2} /$ literatm.[51] Using this solubility along with the rates of tritium production and flow and temperature of Flinabe, Author Sze calculates that the tritium partial pressure over the Flinabe to be about $40 \mathrm{~Pa}$ at the exit of the reactor. This high partial pressure means that recovery of tritium from the Flinabe will not be a technical issue, however, tritium control will be a challenge.

Gas purging is the easiest method for recovering tritium from Flinabe, and a vacuum disengager process is proposed for this purpose. A key step in the process is using a vacuum system to pump tritium from the molten salt coolant. A process proposed for Flibe[52] can be used to recover tritium from Flinabe.

The tritium permeation rate in the primary heat transfer system was calculated by TMAP code as part of the safety analysis.[50] Without mitigation, the high tritium partial pressure over the Flinabe loop in this system would drive tritium permeation into the power conversion system. To address this, we use technologies evaluated for the molten salt reactor program. One is a ceramic coating on the inside of the piping of the primary loop in the primary heat exchanger. The other is a secondary molten salt heat exchanger with a secondary tritium recovery system to provide further isolation and reduction of tritium available for permeation into the steam generator. If the leakage rates from the primary system are high, the allowable 
tritium concentration in the secondary coolants will be low, and the coolant process rates for secondary tritium recovery will be high. In the purging systems, molecular sieves can be used to recover tritium from helium in a helium loop. Water distillation with vapor phase catalyst exchange can be used to recover tritium from water. Whether secondary systems for tritium recovery are affordable has not yet been evaluated.

\section{SAFETY}

Safety assessments[50,53] were performed for our blanket design, but here we have space here only for the conclusions. In the postulated worst-case accident, a total loss-of-site-power leads to loss of plasma control and a plasma disruption that generates electromagnetic currents in the internal components of the vacuum vessel that fail the windows of a diagnostic port or plasmaheating duct and fail a blanket wall by melting caused by runaway electron deposition. Air ingress and its reaction with the hot metal and spilt molten salt mobilizes radioactive material that is transported to the adjoining room by natural convection airflow through the failed port. We determined that the release of oxide aerosol from the advanced ferritic steel, activated Flinabe aerosol, and tritium to the environment does not exceed the no-evacuation dose limit of $10 \mathrm{mSv}$ during the first week of this accident, provided that these releases are stacked. Given the rate of releases from the APEX liquid wall blanket design, the facility must be isolated within an additional two weeks to remain below the 10 $\mathrm{mSv}$ limit. If these releases can not be stacked, then the facility would have to be isolated within five days. Even for ground releases, the time allowed for isolation and facility cleanup is adequate even for manual operation of plant remediation and isolation systems.

The major radiological inventories in this blanket design are the activation products in the advanced ferritic steel structures, the activation products in the Flinabe coolant, and the tritium in blanket and cooling system components. We used the Tritium Migration Analysis Program (TMAP)[54] to predict tritium permeation and inventories for this blanket concept and the major reactor components of the primary heat transport system with the tritium sources being the liquid first wall, the Flinabe blanket and the beryllium multiplier. The total inventory of tritium in the advanced ferritic steel of the primary loop is about $115 \mathrm{~g}$ with $77.6 \mathrm{~g}$ as the in-vessel portion. There is less than $2 \mathrm{~g}$ of tritium in the coolant.

Based on calculations with the MELCOR code[ $[55,56]$ for a loss-of-cooling accident (LOCA) in the quadrant with a failed wall and a loss-of-flow accident (LOFA) in the three quadrants without power, the APEX liquid wall blanket design does not produce high temperatures during a LOCA, but high temperatures $\left(\sim 1100^{\circ} \mathrm{C}\right)$ are reached for a sustained period of time during the LOFA due to the decay heat of Flinabe. Two possible passive measures to remedy this problem are either an in-vessel natural convection decay heat removal system similar to those proposed by Refs. [57,58], or a passively activated valve that drains the Flinabe from the blanket into a tank that is passively cooled.

\section{CLOSING REMARKS AND ACKNOWLEDGEMENTS}

A goal of the APEX study is to investigate the potential of free liquid surfaces in fusion chamber technology with a sufficient level of effort that the design issues can be resolved and an accurate assessment of this potential can be understood. While there are many unanswered questions and directions of investigation that would be important in advancing our chamber design, we believe our preliminary work suggests that tractable solutions for designs with a flowing molten salt could be developed along the lines of the approach reported here.

We are strongly supported by the APEX and ALPS Teams and through significant commitment by the Dept. of Energy's US Fusion Energy Science Program we have utilized expertise in plasma edge modeling, advanced mechanical and systems design, and heat transfer. The work of two authors (TDR and MER) was performed under the auspices of the U.S. Department of Energy by contractW-7405-Eng-48 at University of California Lawrence Livermore National Laboratory.

\section{REFERENCES}

[1] R.E.Nygren et al., Liquid Surface Divertor Designs for Fusion Reactors, elsewhere in this journal

[2] R.E. Nygren et al., A Fusion Reactor Design with a Liquid First Wall and Divertor, to be published in a special issue of FED

[3] M.A. Abdou, the APEX Team, Exploring novel high power concepts for attractive fusion systems, FED 45 (1999) 145-167; see website $<$ http://www.fusion.ucla.edu/APEX/>

[4] R. Mattas and ALPS Team, ALPS - Advanced Limiter-Divertor Plasma Facing Systems, FED. 49-50 (2000) 127; see website $<\mathrm{http} / /$ fusion.anl.gov/ALPS_Info_Center/calls.html $>$

[5] B. Badger, UWMAK-I, A Wisconsin Toroidal Fusion Reactor Design, University of Wisconsin, UWFDM-68, 1973

[6] L. Golubchikov, Development of a Liquid-Metal Fusion-Reactor Divertor with a Capillary-Pore System, JNM 237 (1976) 667-672

[7] J.H. Pitts, A Consistent HYLIFE Wall Design that Withstands Transient Loading Conditions, 4th ANS Top. Mtg. on Tech. of Controlled Nucl. Fusion, King of Prussia, PA, Oct. 14-17, 1980

[8] E. Muraviev, Contact Devices for Divertor and Limiter Systems of Tokamak Reactors. I. Devices with LM Working Surface, Voprosy Atomnoi Nauki I Tekhniki, Ser. Termoyaderniy Sintez', 2, (1980) 57-64

[9] W. Wells, A System For Handling Divertor Ion and Energy Flux Based on a Lithium Droplet Cloud, Nucl.Tech./Fus. 1 (1981) 120

[10] V. Baranov, Liquid Metal Film Flow for Fusion Application, 7th Beer Sheva Int. Sem. on Liquid Metal Magnetohydrodyn., 1983

[11] A. Bond, A Liquid Metal Protected Divertor for a Demo Reactor, 13th Symp.on Fusion Technology, Varese, Italy, (1984) 1225

[12] B. Karasev, LM Contact Divertor for INTOR Tokamak Reactor, 4th All-Union Conf. on Eng. Problems of Fusion Reactors, Leningrad (1988) 225-256 
[13] V. Vodyanyuk, Liquid Metal Tokamak Limiter - Problem Definition and First Results, Plasma Physics, 14, (1988) 628

[14] I. Kirillov, Alternate Concepts of the Divertor Targets Working Materials to the ITER, October 1990, ITER-IL-PC-8-0-18

[15] C. Liao, A Feasibility Assessment of Liquid-Metal Divertors, Fusion Tech., 21, (1992) 1845-1851

[16] S. Mirnov, Liquid-Metal Tokamak Divertors, JNM, 196, (1992) 45-49

[17] V. Chuyanov, Advanced Divertor Plates System Development Proposal, ITER EDA Memo, 1994

[18] E. Muraviev, Liquid-Metal-Cooled Divertor for ARIES, FED 29 (1995) 98-104

[19] E. Muraviev, Open Surface MHD Flow of Liquid Metal Coolant in a Rotating Divertor Target of a Tokamak Fusion Reactor, Magnetohydrodynamics 31 (1995) 306

[20] V. Pistunovich, Research of the Capillary Structure Heat Removal Efficiency Under Divertor Conditions, JNM, 237, (1996) 650-654

[21] V. Lazarev et al., Compatibility of the lithium capillary limiter with plasma in T-11M, ECA, 23J (1999) 845-848

[22] V.A. Evtikhin et al., Energy removal and MHD performance of lithium capillary-pore systems for divertor target application, FED, 49 (2000) 195-199

[23] M.A. Mahdavi, M. Schaffer, Heat Removal with a Liquid Pellet Curtain, Innovative Confinement Concepts Workshop, held at Princeton Plasma Physics Laboratory, April 1998.

[24] M.A. Tillack et al., Engineering Design of the ARIES-RS Power Plant, FED 41 (1998) 491

[25] C.P.C Wong, et al., ARIES Divertor System - Selection and Analysis, FED 38 (1997) 115

[26] T.D. Rognlien and M.E. Rensink, Edge-plasma properties in liquid-wall environments, 8th Int. Workshop on Edge Plasma Theory in Fusion Devices, Helsinki, Finland, Sept. 10-12, 2001

[27] N. Morley et al., to be published in a special issue of FED

[28] T.D. Rognlien, M.E. Rensink, Interactions between liquid-wall vapor and edge plasmas, JNM 290-293 (2001) 312-316

[29] J.N. Brooks, T.D. Rognlien, D.N. Ruzic and J.P. Allain, Erosion/redeposition of lithium-based liquid surface divertors, JNM. 290-293 (2001) 185

[30] R. Bastasz and W. Eckstein, Plasma-Surface Interactions on Liquids, JNM 290-293 (2001) 19-24

[31] R.E Nygren, et al., Design integration of liquid surface divertors, to be published in a special issue of FED

[32] S.Smolentsev, B.Freeze, N.Morley, M.Abdou, Experimental study of turbulent supercritical open channel water flow as applied to the CLiFF concept, FED, to be published

[33] B.Freeze, S.Smolentsev, N.Morley, M.Abdou, Characterization of surface waves and their effect on heat transfer in high $\mathrm{Fr}$, high We open channel turbulent water flow, Int. J. Heat \& Mass Transfer, to be published

[34] J.H. Schaffer, Preparation and handling of salt mixtures for the molten salt reactor experiments, Oak Ridge National Laboratory, Oak Ridge, Tenn., (1971) ORNL-4616

[35] S. Cantor, Density and Viscosity of Several Molten Flouride Mixtures, Oak Ridge National Lab., Oak Ridge, Tenn., (1973) ORNL/TM-4308; see also S. Cantor et al., Viscosity and Density in LiF-BeF2 Solutions, J. Chem. Phys., 50 (1969) 2874

[36] S. Cantor, S.D.S. Hsu, W.T. Ward, Vapor Pressures of Flouride Melts, in Reactor Chem. Div. Annual Progress Report, Oak Ridge Nat. Lab., Oak Ridge, Tenn., (1965) ORNL-3913 24-26

[37] R.W. Moir, M.G. Adamson, R.O. Bangerter, R.L. Bieri, R.H Condit, et al., HYLIFE Progress Report, Lawrence Livermore Nat. Lab., Livermore, CA (1991) UCID-21816; see also R.W. Moir et al., HYLIFE-II: A Molten-Salt Inertial Fusion Energy Power Plant Design--Final Report, Fusion Tech., 25, 5-25, 1994.

[38] D.L. Smith, et al., Blanket Comparison and Selection Study (final report), Argonne Nat.l Lab., Argonne, IL (Sept. 1984) ANL-Report, ANL:FPP-84-1; see also D.L. Smith, C.C. Baker, D.K. Morgan, M.A. Abdou, et al., Overview of the Blanket Comparison and Selection Study, Fusion Tech. 8,1 (1985) 10-44
[39] D.K. Sze, K. McCarthy, M. Sawan, M. Tillack, A. Ying, S. Zinkle, Flibe assessments, Fusion Tech. 2,2 (2001) 746-752

[40] R. L. Klueh, et al. Microstructure and Mechanical Properties of Oxide Dispersion-Strengthened Steels, DOE/ER-0313/28, June 2000; see also R.L. Klueh, P.J. Maziasz, I.S. Kim, L. Heatherly, D.T. Hoelzer, N. Hashimoto, E.A. Kenik and K. Miyahara, Tensile and Creep Properties of an Oxide DispersionStrengthened Ferritic Steel, JNM 307-311 (2002) 773-777

[41] S. Ukai and M. Fujiwara, Perspective of ODS Alloys Application in Nuclear Environments, JNM, 307-311 (2002) 749-757

[42] M.Z. Youssef, N.B. Morley, and D-K Sze, Nuclear Performance of the Thin-Liquid FW Concept of the CLiFF Design, Fusion Tech., 39, 2 part 2 (2001) 839-845

[43] M.Z. Youssef, M.E. Sawan, and D.-K. Sze, The breeding Potential of Flinabe and Comparison to Flibe in CLiFF High Power Density Concept, FED 61-62 (2002) 497-503

[44] M.Z. Youssef, M.S. Sawan, Component Lifetime Comparison and Waste Volume In CLiFF Sn/Flibe and $\mathrm{Sn} / \mathrm{LiPb}$ Blankets, FED, 63-64 (2002) 277-283

[45] M.Z. Youssef and M.A. Abdou, Heat Deposition, Damage, and Tritium Breeding Characteristics in Thick Liquid Wall Blanket Concepts, FED, 49-50 (2000) 719

[46] M.Z. Youssef and M.S. Sawan, Radwaste Volume In Lithium And Flibe LW And Comparison To Conventional SW Concepts, FED 63-64 (2002) 263-269.

[47] W. W. Engle, ANISN: A One Dimensional Discrete Ordinates Transport Code with Anisotropic Scattering, Report K-1693, Union Carbide Corporation, 1967.

[48] A.B. Pashchenko, Completion of FENDL-1 and Start of FENDL2, INDC(NDS)-352, IAEA Nuclear Data Section, International Atomic Energy Agency, March 1996.

[49] M.Z. Youssef, N. Morley, A. El-Azab, X-Ray Surface and Volumetric Heat Deposition and Tritium Breeding Issues in Liquid-Protected FW in High Power Density Devices, Fusion Tech., 34 (1998) 697-705

[50] B. Merrill et al., "Safety Assessment of Two Ferritic Steel Molten Salt Blanket Design Concepts" to be published in a special issue of FED

[51] A. P. Malinauskas and D.M. Richardson, MSR Program Semiannual Progress Report, Oak Ridge National Laboratory, Oak Ridge, TN (Feb., 1972) ORNL-4782

[52] T.J. Dolan, G. R. Longhurst and E. Garcia-Otero, Vacuum Disengager Design for Tritium Removal from Flibe in the HYLIFE-II Reactor, Fusion Tech. 21 (1992) 1949

[53] B.J. Merrill, D.K. Sze, H.Y. Khater, E.A. Mogahed, Safety implications of CliFF liquid metal first walls, FED 63-64 (2002) 285-293

[54] B. J. Merrill, J. L. Jones, D. F. Holland, TMAP/MOD1: Tritium migration analysis program code description and user's manual, Idaho Nat. Eng. Lab. Report, EGG-EP-7407, April 1988

[55] R. O. Gauntt, et al., MELCOR Computer Code Reference Manuals: Version 1.8.4, NUREG/CR-6619, Vol. 2, Rev. 1, July 1997, pp. HS-RM 37-41.

[56] B. J. Merrill, R. L. Moore, S. T. Polkinghorne, D. A. Petti, Modifications to the MELCOR code for application in fusion accident analysis, FED 51-52 (2000) 555-563

[57] C. P. C. WONG, et al, Evaluation of the Tungsten Alloy Vaporizing Lithium First Wall and Blanket Concept, Fusion Tech. 39 (2001) 815-822.

[58] D. Steiner, et al., ARIES-RS safety design and analysis, FED 38 (1997) $189-218$ 